\title{
Marketing direto e a estratégia competitiva da indústria de cosméticos
}

Esta pesquisa buscou referência teórica sobre marketing direito com os principais autores do tema. A metodologia utilizada foi a bibliográfica, com pesquisa exploratória para auxiliar no entendimento do contexto, utilizando a Empresa Avon e seus principais meios de utilização do marketing direto por meio de catálogos atualizados e sua evolução tecnológica disponível online ou pelo site, seja para atendimento aos seus clientes como das revendedoras, por meio da evoluções tecnológicas e a obtenção de vantagem competitiva, baseada em baixo custo e pela ampliação do portfólio produtos.

Palavras-chave: Marketing direto; Vantagem; Competitiva.

\section{Direct marketing and the competitive strategy of the cosmetics industry}

\begin{abstract}
This research sought theoretical reference on law marketing with the main authors of the theme. The methodology used was bibliographic, with exploratory research to help in understanding the context, using the Avon Company and its main means of using direct marketing through updated catalogs and its technological evolution available online or through the site, either to meet their needs. customers as well as resellers, through technological evolutions and the achievement of competitive advantage, based on low costs and the expansion of the product portfolio.
\end{abstract}

Keywords: Direct marketing; Advantage; Competitive.

Topic: Marketing e Estratégias Mercadológicas

Reviewed anonymously in the process of blind peer.
Received: 01/02/2019

Approved: 01/05/2019
Beatriz Monica Schuchmann

Faculdade Sumaré, Brasil

http://lattes.cnpq.br/9901614137339518

bia.schuchmann@gmail.com
Referencing this:

SCHUCHMANN, B. M.. Marketing direto e a estratégia competitiva da indústria de cosméticos. Entrepreneurship, v.3, n.1, p.1-8, 2019. DOI: http://doi.org/10.6008/CBPC2595-4318.2019.001.0001 


\section{INTRODUÇÃO}

Este trabalho irá falar sobre a evolução do marketing direto, pois os avanços tecnológicos e com o público buscando meios mais rápidos e diretos de atendimento, com o aumento dos nichos de mercado, falta de tempo e grandes filas, são alguns dos motivos para a ampliação do marketing direto. $\mathrm{O}$ marketing direto é a construção de um relacionamento empresa-cliente, que através do CRM (customer relantionship management), sendo um banco de dados para auxilio no gerenciamento das informações de seus clientes, permitir traçar um perfil de seu público alvo.

Pelo marketing direto estar se tornando o meio mais utilizado pelos consumidores atuais, sendo os mais utilizados mala direta, catálogos, telemarketing, tv interativa, quiosques, sites, telefones e dispositivos moveis, traz muitos benefícios para o consumidor pela praticidade de poder comparar vários itens entre catálogos eletrônicos e em sites de compras online, otimizando desta forma seu tempo e dinheiro. Para as empresas também se caracteriza vantagens pelo benefício de identificar seu público e construir um relacionamento a longo prazo através de descontos e lembretes em datas importantes para ambas.

Com o aumento populacional e com a nova geração de consumidores que estão nascendo, as empresas estão buscando através do marketing direto aliado a internet gerar uma nova fidelização de suas marcas. Esse trabalho tem como objetivo, conhecer e entender as funcionalidades do marketing direto. Como pode se tornar uma vantagem competitiva, frente à grande concorrência e os avanços gerados pela tecnologia.

\section{METODOLOGIA}

Esse trabalho irá utilizar como método a pesquisa bibliográfica, que se caracteriza pelo desenvolvimento do conteúdo através de livros e artigos científicos, também sendo uma pesquisa exploratória tendo como característica a análise de exemplos para auxiliar no entendimento do contexto de acordo com Gil (2002).

\section{REVISÃO TEÓRICA}

A palavra Marketing deriva de Market, em inglês, que significa mercado. É utilizada esta expressão por ser voltado exatamente para o mercado consumidor. O conceito de marketing surgiu na década de 1950 no pós-guerra, quando os avanços da industrialização mundial ampliaram o mercado e maior disputa entre as empresas. Não era suficiente produzir com qualidade e a custo competitivo, os clientes queriam o que lhe proporcionasse melhor custo e benefício a sua escolha (BRETZE, 2010).

Um dos conceitos de marketing, segundo Kotler (2012), é suprir necessidades gerando lucro, por envolver a identificação e a satisfação das necessidades humanas e sociais. Porém, Peter Drucker mostra de outra forma o conceito do marketing: pode-se considerar que sempre haverá a necessidade de vender. Mas o objetivo do marketing é tornar supérfluo o esforço da venda. O objetivo do marketing é conhecer e entender o cliente tão bem que o produto ou o serviço possa se adequar a ele e se vender sozinho. De 
maneira ideal, o marketing deveria resultar em um cliente disposto a comprar. A única coisa necessária, então, seria tornar o produto disponível (KOTLER, 2012).

A estratégia competitiva, segundo Porter (1989), deve surgir da compreensão das regras dos concorrentes pra que se possa determinar a atratividade, pois em uma empresa seja ela de produtos ou serviços, as regras da concorrência estão englobadas em cinco forças: a entrada de novos concorrentes; a ameaça de substitutos; o poder de negociação dos compradores; o poder de negociação dos fornecedores; e a rivalidade entre os concorrentes existentes.

Essas cinco forças competitivas iram determinar se a empresa ou indústria serão capazes de ter seu retorno de seus investimentos, gerando um lucro para a mesma. Pois o comprador dirá seu poder de compra, como também os produtos que podem ser substituídos por ameaças, o poder dos fornecedores na negociação dos valores de matéria-prima ou insumos, a tendência a concorrência, pois com essas informações será possível colocar limites para se controlar futuros ou atuais entrantes no seu mercado. (PORTER, 1989).

Mas Porter (1989) afirma que o fundamental da vantagem competitiva independentes dos seus pontos fortes e fracos em comparação com seus concorrentes, são dois tipos básicos: baixo custo ou diferenciação. Pois para Porter, quando duas ou mais empresas estão brigando para liderar o mercado ou abaixa seus custos, correndo um grande risco devido as consequências de sua rentabilidade, ou ela tentar ser líder no que faz atuando na diferenciação, com um ou mais atributos que seus compradores valorizam para ser recompensada com um preço mais alto.

Os seres humanos possuem necessidades básicas como alimentação, vestuário, abrigo e segurança, ah também as necessidades sociais de pertencer ao um grupo e as necessidades individuais de poder expressar suas ideias, sentimentos e obter conhecimento (KOTLER, 2007). Com base nas necessidades moldadas pela cultura e pela personalidade de cada um, será gerado o desejo, quando apoiado pelo poder de compra, ira de forma a demanda, no qual a pessoas querem o melhor conjunto de valor e satisfação como retorno.

Por volta da metade do século XIX, Aaron Montgomery Ward querendo ter um marketing mais alternativo, tentando ser mais direto a seus clientes, criou o primeiro catálogo com relógios banhados a ouro oferecidos a agentes ferroviários e assim nasceu a Sears, Roebuck e Company a mais antiga empresa a utilizar o marketing direto.

Uma das definições do marketing direto utilizada pela Direct Marketing Association (DMA) sendo um sistema interativo de marketing que utiliza umas ou mais mídias para produzir uma resposta ou transação mensurável, em qualquer lugar (BRETZKE, 2010). O marketing direto visa atingir seus potencias consumidores no momento que eles desejam fazer a solicitação, também tornando mais rápida e mensurável a resposta de suas campanhas e assim mais rentáveis (BRETZKE, 2010).

Analisando cada um dos canais de marketing direto (BRETZKE, 2010), tem-se: Mala direta: se caracteriza pelo envio de oferta, anuncio, lembrete ou algum item direcionado a uma pessoa em um endereço especifico. Sendo um meio um pouco mais caro para as empresas, porém promissor devido a 
seleção dos contatos; Marketing de catalogo: São catálogos de toda a linha de mercadoria oferecida por uma empresa, normalmente enviados de forma impressa, algumas vezes em dvd ou disponibilizados online. Muitas empresas aliaram os catálogos com sites para garantir uma venda mais eficaz; Telemarketing: é o uso de operadores ou centrais telefônicas realizando ligações para atrair novos clientes, vender para clientes atuais ou prestar serviços. O telemarketing se caracteriza por dois tipos o receptivo, no qual o cliente entra em contato com os operadores, e o ativo para contatar clientes atuais ou para novos clientes.

Internet: caracteriza-se como o marketing online sendo um conjunto de transações eletrônicas que permitem a troca de produtos ou serviços direcionada ao consumidor. Incluindo o uso de e-mails, pop-up, hot site, splash page, floater, streaming, intersticial, patrocínio e Broasdcast; Mídias sociais: pelo compartilhamento de mídias, textos, imagens, arquivos de áudio ou vídeo através de redes sociais. As principais mídias sociais: comunidades e fóruns on-line, bloggers (diários online) e as redes sociais (facebook, Twitter e Youtube); Outros meios: os jornais e revistas que trazem em suas páginas milhares de anúncios.

Os anúncios em rádios e televisão que estão disponíveis 24 horas por dia. Boca a boca: onde cada pessoa fala para outras o que viu ou experimentou um produto ou serviço, sendo uma mídia gratuita ou mídia espontânea; e Marketing interativo: se caracteriza pela comunicação direta com seus clientes através de canais eletrônicos, possibilitado através dos avanços da internet (KOTLER, 2012). As vantagens do marketing interativo é o envio de mensagens personalizadas para cada consumidor, a internet também mostra seus resultados muito mais rapidamente, pois é possível saber quanto tempo, o que o cliente olhou e aonde foram depois (KOTLER, 2012).

Através da internet as empresas podem chegar mais longe atingindo um número maior de pessoas do que lojas físicas. As categorias mais utilizadas pelas empresas para marketing interativo são: sites, anúncios em sites de buscas, banners, e-mails e o mais recente o mobile marketing (através de telefones celulares). Desta forma iram garantir seus objetivos de comunicação ou venda mais rapidamente (KOTLER, 2012).

O marketing direto apresenta algumas características diferentes do marketing tradicional, que ajudam nas análises das informações, pois qualquer aplicação de marketing direto irá utilizar algumas destas combinações segundo Bretzke (2010), sendo elas: A lista: engloba nome, endereço e perfis com algo em comum segundo Harper (1986), sendo a base para a mala direta.

Existem duas categorias de listas a interna (house lists) e a externa que e pode ser dividida em mais duas categorias básicas, as listas compiladas tais como lista telefônica, associações de classes, entre outras, e as listas de respondentes que são formadas por pessoas ou empresas que responderam a alguma ação de marketing direto como vendas, doação, entre outras.

A database Marketing: sendo a evolução das análises da lista incorporada a estatísticas. Umas das funções mais importantes da database marketing são medir resultados. Cada fase de uma campanha pode ser medida, sendo possível obter um conjunto de informações sobre seu cliente, as mídias envolvidas, ofertas, e resposta dessas campanhas. 
CRM (customer Relationship management/gerenciamento do relacionamento com os clientes) O CRM é uma tecnologia que permite capturar os dados do cliente e de todos os seus contatos e transações, envia-los a um banco de dados, analisar e utilizar de forma inteligente cada informação, através da informática (call center, help desk e assistência técnica) sendo um canal ligado ao cliente (BRETZE, 2010). CRM é um processo interativo que visa transformar informações sobre os clientes em um relacionamento mais positivo de acordo com Swift (2001).

\section{Estudo prático}

A partir deste ponto vamos apresentar uma empresa chamada Avon que durante seus anos de existência evoluir seus métodos de trabalho através dos avanços do marketing direto. A empresa Avon teve seu início em meados de 1886 como seu nome original de California Perfume Company (CPC) nos Estados Unidos através de um livreiro chamado David H. McConnel, que cria suas formulas de seus perfumes e recruta algumas donas de casa da região para trabalharem com ele vendendo seus produtos de porta em porta.

Somente em 1896 foi criado o primeiro folheto com os produtos da empresa para que fosse mais fácil realizar a venda, o folheto se caracteriza no marketing direto como um catalogo como já mencionado anteriormente é um dos primeiros métodos utilizados, no caso da empresa Avon o catalogo era enviado de maneira impressa para seus revendedores pudessem mostrar um maior número de produtos a suas clientes. Como as clientes gostaram deste método de abordagem, a empresa Avon resolve ampliar seu mercado e conquistar mais revendedoras para o ramo criando um novo catalogo mais agora voltado para as revendedoras com dicas, conselhos de como aumentar suas vendas e notícias da evolução da empresa em si.

Em 1906 a empresa Avon resolve realizar uma parceria realizando anuncio na revista Good Housekeeping, este método como já mencionado anteriormente como outras mídias é realizado para divulgar sua marca a um maior número de clientes. Neste mesmo ano, é lançado um folheto a qual suas páginas possuir cores, deixando assim mais bonito visualmente e atrativo para suas clientes; também aproveita para ampliar seu mercado de atuação indo para venda no catalogo de corantes e aromatizantes para bolos e doces.

Entre 1928 e 1941 os Estados Unidos passa por um profundo declínio econômico a empresa até então Califonia Perfume Company se mantém ativa no mercado e expansão, resolve então adotar o nome 'Avon', oficialmente. O nome Avon teve sua referência em um rio que passava na cidade natal de William Shakespeare. Em 1953, a empresa Avon implementa mais uma ferramenta de marketing direto lançando seu primeiro comercial de televisão. Na década de 60 devido à propaganda boca a boca estar trazendo mais clientes à empresa e gerando uma 'boa fama' e alcançando um número maior de revendedora a Avon adota um novo Slogan chamado a Avon chama. No Brasil a empresa Avon começa a atual nos anos 60 e utilizando o slogan a Avon chama, traz a alusão a ato da revendedora que vai até sua casa chamar o cliente para a compra. 
Durante os anos, a empresa Avon ganha mercado e já atua em diversos países e ao chegar à China em 1990 instala a venda direta sem a necessidade do catalogo, sendo a venda direta para o cliente. Em 1996 resolve ampliar seu mercado mais uma vez agora nos Estados Unidos é realizada a venda de seus produtos através da internet em seu website oficial, sendo o primeiro site voltado para o público B2C (business to consumer). Nos anos 2000, a Avon enfrenta uma nova crise financeira e para sobreviver no mercado resolve dar mais autonomia para suas revendedora criando um site para realizar seus pedidos e ter um melhor feedback.

Procurando-se aprimorar, a Avon ganha cada vez mais mercado atuando em mais de 100 países e para garantir que todos possam ser bem atendidos, a empresa oferece o catalogo impresso a seus clientes, o site para compra direcionado a clientes, o site para suas revendedoras a qual se utiliza de um sistema de CRM para poder desta forma oferecer um melhor atendimento e agilizar seus pedidos e entregas, e também tentar capturar novas revendedoras, comerciais de televisão, serviços de telemarketing para clientes e revendedoras, atuando nas redes sócias para divulgação de seus produtos e o bom boca a boca que sempre ajudou a empresa a evoluir e ganhar mercado.

A empresa Avon não tem loja física própria, porém, algumas revendedoras vendo a necessidades de suas clientes em adquirir seus produtos à pronta entrega, abriram lojas que disponibilizam todos os produtos em lojas físicas e conseguem realizar as mesmas promoções realizadas nos folhetos da empresa. Com base na história da empresa Avon, reunimos algumas revendedoras que atuam em nossa região, que realizam vendas de produtos da Avon e de seus principais concorrentes, para se obter um parecer sobre as ações de marketing direto visto por quem atua no ramo.

De acordos com as revendedoras, os principais clientes da Avon são jovens até seus 24 anos que gostam de adquirir produtos de maquiagem, devido a seus valor e qualidade. Também foram citadas as senhoras a partir de 35 anos que gostam dos produtos voltados para anti-idade e os utensílios de casa e moda. Com relação à propaganda da marca, elas confirmam ser muito importante, pois as clientes, em sua maioria, já as procuram sabendo o que pretender adquirir, seja porque já viram em propagandas, ou devido a anos de existência da marca que já gera uma confiança passada de geração para geração.

Outro ponto importante citado é que, caso uma nova cliente queira adquirir os produtos e não saiba onde encontrar uma revendedora para analisar seu catalogo, o site da própria empresa Avon disponibiliza localizar as mais próximas da sua região, e uma vez realizada a compra com essa revendedora dificilmente são trocadas, devido à confiança. As revendedoras também informaram que, quando se trata de perfume, a concorrente 'O Boticário' ganha; segundo as mesmas de cada 10 clientes 8 preferem comprar da concorrente o Boticário. Outro concorrente apontado para clientes de maquiagem é a Mary Kay sendo um diferencial grande de qualidade e preço, para cremes foi citada a Natura também como obtendo melhor qualidade que os produtos da empresa Avon.

E por último, mas não menos importante, as revendedoras disseram que está difícil de trabalhar com a Avon devido a atrasos nos pedidos, quando as faltas no estoque somente são avisadas no ato da entrega de suas encomendas e que muitas clientes acabam indo para as empresas concorrentes para não terem que 
correr este risco. Analisando o cenário como um todo, as revendedoras informaram que em sua opinião a Avon ganha mercado por ser uma empresa de baixo custo e uma qualidade razoável comparada com suas concorrentes mais fortes.

Através de pesquisa nas redes sócias, foi verificado que a empresa Avon disponibiliza uma ferramenta chamada Widget (aplicativo), que permite compartilhar o folheto de produtos com todos os seus contatos, e a partir desta função as revendedoras recebem o pedido eletronicamente. Essa função está disponível para as redes de Facebook, Instagram, Twitter, Googlet, Wordpress, Blogger, etc.. No Facebook, a empresa criou também um aplicativo chamado 'vitrine da beleza Avon' para as revendedoras destacarem os produtos que elas acham que tem maior destaque com seus contatos.

A empresa Avon também está disponibilizando na própria página da empresa espaço para treinamento virtual, notícias sobre seus produtos, ofertas e as ações sociais da empresa, não esquecendo o folheto voltado somente para revendedoras que concede descontos maiores nos produtos, para garantir um ganho maior a suas revendedoras e programa 'estilo pirâmide', com prêmios para as revendedoras que mais realizarem maior volume de vendas.

Em reportagem ao Valor econômico em 2016 Legher presidente da Avon até 2018 afirma que a empresa tem ações visando a concorrência: 'Estamos investindo em marca, em um bom portfólio e na segmentação de perfil das vendedoras', pois a Avon é muito conhecida no Brasil, mas a concorrência tem aumentado. A Natura, em seu relatório anual (2005), afirma que tem investimento em tecnologia, o que permite uma excelente eficiência operacional, que está centrada na diferenciação dos seus produtos em relação aos da Avon e outras empresas do ramo, e possui um forte investimento em pesquisa e desenvolvimento, o que permite um grande números de lançamento anuais, em 2005 foram 156, por exemplo.

\section{CONCLUSÕES}

Bretzke (2010) coloca, como um dos canais de marketing direto, o catálogo. Nos dias atuais, também disponibilizados online, aliados aos sites para garantir uma venda mais eficaz. Na Avon, o catálogo surgiu para oferecer um marketing alternativo, para ser mais direto com seus clientes, e com base neste método, a empresa iniciou oficialmente em 1886, com seu folheto aliado à venda de porta em porta, empresa pioneira neste tipo de venda, e conseguir, com os avanços tecnológicos, ainda manter esse método que é uns dos mais antigos do marketing.

O marketing direto visa atingir seus potencias consumidores no momento que eles desejam fazer a solicitação, também tornando mais rápida e mensurável a resposta de suas campanhas e assim mais rentáveis (BRETZKE, 2010). A Avon buscando atingir seus consumidores no momento que desejam comprar, oferece vários canais de atendimento para garantir que seus clientes serão atendidos na melhor hora e da melhor forma, seja pelo folheto, pela internet, pelas revendedoras e as parcerias em lojas físicas. Ao meu ponto de vista a empresa tenta atuar da melhor forma possível para atender seus clientes no momento da 
sua necessidade e dando suporte seja por telefone, e-mail, redes sócias ou presenciais para suprir da melhor forma as necessidades de suas revendedoras e posteriormente suas clientes.

Segundo Bretzke (2010) o 'boca a boca', onde cada pessoa fala para as outras o que viu ou experimentou um produto ou serviço, sendo uma mídia gratuita ou mídia espontânea. A empresa Avon se valoriza deste benefício boca a boca para passar de geração em geração. Esse é um dos diferenciais da Avon ele consegue cativar seus clientes que a avó usou, e fala bem para a filha, que consequentemente conta para a vizinha que conta para amiga, talvez com cada vez mais tecnologia envolvida isso mude como já tem mudado, mais ainda é um ponto muito importante na marca, aliado as suas revendedoras que tem um contato mais humano e mais próximo de suas clientes.

Para Porter (1989) afirma que o fundamental da vantagem competitiva independentes dos seus pontos fortes e fracos em comparação com seus concorrentes, são dois tipos básicos: Baixo custo ou diferenciação. Segundo a pesquisa realizada com as revendedoras da empresa Avon elas informaram que em sua grande maioria, as clientes que procuram produtos da empresa Avon estão em busca de preço mais acessível e uma qualidade razoável. A empresa Avon, devido à grande concorrência em seu ramo de atuação, que cada vez tem se ampliando o portfólio de produtos de beleza, perfumes, utensílios de casa, livros, sapatos e até roupas, tem ganhado em alguns requisitos como custo mais baixo para a empresa e consequentemente valores reduzidos para seus clientes, não deixando tanto a desejar a seus clientes. Concorrentes como a Natura investiram em desenvolvimento de novos lançamentos.

\section{REFERÊNCIAS}

BRETZKE, M.. Comportamento do cliente. In: DIAS, S. R.. Gestão de marketing. 2 ed. São Paulo: Saraiva, 2010. p.3794.

DIAS, S. R.. Gestão de Marketing. 2 ed. São Paulo: Saraiva, 2010.

GIL, A. C.. Como elaborar projeto de pesquisa. 4 ed. São Paulo: Saraiva, 2002.
KOTLER, P.. Administração de Marketing. 12 ed. São Paulo: Pearson Prentice Hall, 2006.

PORTER, M. E.. Vantagem competitiva: Criando e sustentando um desempenho superior. 37 ed. Rio de Janeiro: Elsevier, 1989.

SWIFT, R.. CRM, customer relationship management: o revolucionário marketing de relacionamento com o cliente. Rio de Janeiro: Campus, 2001.

A CBPC - Companhia Brasileira de Produção Científica (CNPJ: 11.221.422/0001-03) detém os direitos materiais desta publicação. Os direitos referem-se à publicação do trabalho em qualquer parte do mundo, incluindo os direitos às renovações, expansões e disseminações da contribuição, bem como outros direitos subsidiários. Todos os trabalhos publicados eletronicamente poderão posteriormente ser publicados em coletâneas impressas sob coordenação da Sustenere Publishing, da Companhia Brasileira de Produção Científica e seus parceiros autorizados. Os (as) autores (as) preservam os direitos autorais, mas não têm permissão para a publicação da contribuição em outro meio, impresso ou digital, em português ou em tradução. 